\title{
Treatment Response in First-episode Schizophrenia
}

\author{
Rebecca Schennach, Michael Riedel, Richard Musil, Hans-Jürgen Möller \\ Department of Psychiatry and Psychotherapy, Ludwig-Maximilians-University Munich, Munich, Germany
}

\begin{abstract}
First episode schizophrenia (FES) patients tend to be more responsive to treatment. An adequate response has been associated with a favourable long-term course in FES patients. Yet, despite the generally very favourable response profile around one quarter of the patients shows persisting symptoms of psychosis. To improve the outcome and course of psychosis great effort has emerged in identifying biological and clinical variables associated with non-response in order to identify non-responders as early as possible and adopt specific treatment strategies improving illness outcome. Different antipsychotic treatment regimens have been evaluated in terms of their efficacy in reducing symptoms of FES with psychological interventions gaining increasing importance in the treatment concept of patients suffering from their first illness episode. Therefore, aim of this review is to summarize current evidence on the response patterns, the most important predictors of response/non-response as well as on effective treatment interventions in FES patients.
\end{abstract}

KEY WORDS: First-episode schizophrenia; Response; Course of illness; Outcome; Predictors; Treatment interventions.

\section{INTRODUCTION}

The first episode of psychosis typically occurs during adolescence and early adulthood, a vulnerable life stage in which one deals with one's own future and personal interests including education and vocation as well as the development of relationships. ${ }^{1,2)}$ This contributes to the immense psychosocial and economic burden of this illness for the patient, his family and the society. ${ }^{3)}$ Research results have consistently shown that an adequate treatment within the early stages of psychosis is of great importance in terms of the course and outcome of the illness. ${ }^{4,5}$ Today, the optimal treatment is based on the early administration of antipsychotics ${ }^{6}$ and response to treatment within the first 1-3 months has been found to be highly predictive of subsequent partial or non-remission of symptoms. ${ }^{7)}$

It is generally accepted that first-episode patients tend to be more responsive to antipsychotic compounds compared to multiple episode patients ${ }^{8)}$ resulting in specific therapeutic recommendations for this patient subgroup in current treatment guidelines. ${ }^{9)}$ But even though most pa-

Received: May 16, 2012 / Accepted: May 31, 2012

Address for correspondence: Rebecca Schennach, MD Department of Psychiatry and Psychotherapy,

Ludwig-Maximilians-University Munich, Nussbaumstreet 7, 80336,

Munich, Germany

Tel: +49-89-5160-5869, Fax: +49-89-5160-5774

E-mail: Rebecca.Schennach@med.uni-muenchen.de tients with first-episode psychosis respond very well to antipsychotic medication with estimates ranging as high as $87 \%{ }^{10)}$ treatment in first-episode patients also includes patients with partial or complete non-response. A growing body of evidence underlines the importance of an early identification of non-responders to antipsychotic treatment for it could prevent unnecessary persistence with ineffectual compounds and with this reduce the duration of hospitalization, the level of care required ${ }^{11)}$ and most important it could prevent biological and psychosocial deterioration. ${ }^{12)}$ Today, several biological and clinical predictors of early non-response have been identified and resulted in specific treatment recommendations in order to improve the outcome of the psychosis such as early intervention programs. Besides, several studies have evaluated different antipsychotic and psychosocial treatment strategies in order to identify effective and optimal treatment regimes again with the aim of ensuring a favourable long-term outcome.

On the background of the significance of an adequate and timely response to antipsychotic treatment when suffering from the first episode of psychosis, this review provides an overview on the current knowledge of response patterns in first-episode patients, and summarizes the most important predictors of response/non-response as well as the current evidence on effective treatment strategies. 


\section{RESPONSE PATTERNS, TIME COURSE OF TREATMENT RESPONSE AND OUTCOME IN FIRST-EPISODE PATIENTS}

Over the past years it has been acknowledged that response and outcome of schizophrenia vary and are heterogeneous. ${ }^{13)}$ The main challenge discussing current research evidence on response in patients suffering from their first episode of schizophrenia (FES) lies in the differing response criteria applied in the respective studies. As suggested by Leucht and Kane, ${ }^{14)}$ response can be defined as a clinically meaningful improvement of the patient's psychopathological symptoms irrespective of the fact whether he or she is still symptomatic. Usually, predefined cutoffs in terms of percentage reductions of the baseline score on a psychopathology rating scale are applied in order to evaluate response to treatment. ${ }^{14)}$ One problem is that especially in FES patients a consensus on how much improvement response really is, is still standing out. Today, the most accepted definition of response in schizophrenia research in general is a $\geq 50 \%$ improvement in the respective rating scale from baseline to endpoint. ${ }^{15)}$ Future studies should analyse if this response criterion is also appropriate in the evaluation of FES patients. The differing response criteria applied resulting in differing study results should be kept in mind when discussing current research data on response in FES patients.

Traditionally it is believed that the course and prognosis of the patients can be roughly divided into three categories, namely in one (approximately $25 \%$ of the patients) with full response to treatment leading to a recovery from the first illness episode, in one with recurrent illnesses in form of exacerbations and remissions (around $50 \%$ of the patients) and in another group of patients with an unfavourable course and incomplete response and recovery from the first episode ( $25 \%$ of the patients). ${ }^{16)}$ The first treatment intervention in FES patients is therefore critical, for the efficacy of treatment of the first episode is associated with the prognosis of the illness. ${ }^{12)}$ A large number of randomized-controlled drug trials has shown that an adequate treatment with antipsychotic compounds is linked with a rapid improvement of psychopathological symptoms in FES patients. ${ }^{17,18)}$ In contrast, the specific response pattern and time course of response in FES patients has only been examined by few authors. Emsley et al. ${ }^{11)}$ are among those analysing the time course of antipsychotic treatment response by examining 522 FES patients over a median treatment length of 206 days and defining response as a $\geq 20 \%$ reduction in the total score of the Positive and Negative Syndrome Scale (PANSS). The authors found that the time to response varied considerably with $23.3 \%$ of the patients achieving response during the first week of treatment, $23.3 \%$ at week $2,18.5 \%$ at week 3 , and $12.5 \%$ at week 4 , but with $22.5 \%$ of the patients not responding until after 4 weeks and $11.5 \%$ of those patients not responding until after 8 weeks. ${ }^{11)}$ And when evaluating the time course and biological correlates of treatment response in FES patients, Lieberman et al. ${ }^{16)}$ stated that they were surprised by the length of time required for patients to respond sufficiently and recover. In their study they examined 70 patients and identified response in $83 \%$ patients defined as a rating of mild or less in three of four positive psychotic symptom items, and an improvement of the rating on the Clinical Global Impression Scale (CGI) of much improved or very much improved after 6 weeks. ${ }^{16)}$

Although it seems as if a substantial proportion of FES patients does not improve early after receiving antipsychotics, recent research suggests that the onset of antipsychotic drug action occurs within the first 24 hours of treatment initiation. ${ }^{19,20)}$ However, up to today no consensus has been reached on the specific time period after which a patient should be withdrawn from the respective treatment regimen in case of non-response. Generally, treatment guidelines recommend to leave a patient on his treatment for around 4-6 weeks before evaluating response. ${ }^{9)}$ But increasing evidence has emerged that response within the first two weeks of treatment reliably predicts subsequent response suggesting that a change of treatment might be necessary already after the second treatment week in order to ensure a favourable long-term response and outcome. ${ }^{21,22)}$

In this context the question arises whether limited early psychopathological improvement in FES patients is also associated with an ultimate lack of treatment response or, as suggested by the above discussed results, in FES patients it might take several weeks before a satisfying level of response is achieved. Derks et al. ${ }^{23)}$ were among the first to explicitly examine early response to antipsychotic treatment in FES patients concurrently trying to answer the question on whether a patient should be switched to a different antipsychotic drug after 2, 4, or 6 weeks of non-response within the European First Episode Schizophrenia Trial (EUFEST). The authors were able to evaluate 299 first-episode patients over a time period of 12 months and confirmed earlier findings that the 2-week measures were associated with achieving remission after 1 year (defined following the criteria by the Remission in Schizophrenia Working Group). ${ }^{23)}$ The prediction of re- 
mission was found to significantly improve by the inclusion of the 4- and 6-week assessments. However, given that the prediction accuracy was only modest, Derks et $a l{ }^{23)}$ critically question whether this leads to a clinically significant prediction. Only very recently, Gallego et al. ${ }^{24)}$ reported on the time to treatment response in 112 FES patients randomly designed to olanzapine or risperidone. Response was defined as a rating of mild or better on all of the positive symptom items of the Schedule for Affective Disorders and Schizophrenia Change Version with psychosis and disorganization items. The authors found and estimated cumulative response rates of $39.59 \%$ by week 8 and $65.19 \%$ by week 16 , but they did not find any level of percentage symptom reduction at weeks 2,4 or 8 to be a clinically useful predictor of response by week $16 .{ }^{24)}$ Possibly, the predictive power of early response in FES patients might depend on the assessment time point. Within our own working group and a trial performed by the Competence Network on Schizophrenia in Germany, we were able to show that when examining a short-term treatment phase ( 8 weeks acute treatment comparing the efficacy of risperidone and haloperidol) patients improving at least $30 \%$ in the PANSS within the first two treatment weeks could be reliably identified to be the ones achieving response ( $\geq 50 \%$ PANSS improvement from baseline to endpoint) and remission (defined following the criteria by the Remission in Schizophrenia Working Group) at endpoint. ${ }^{25)}$ However, when trying to predict response one year after the patients were discharged from hospital, the psychopathological improvement beginning with week 6 of treatment was the earliest time point reliably predicting response at week $52 .{ }^{26)}$ Taken together, current data suggest that an early response to antipsychotic treatment can be observed in FES patients and is a valid predictor of subsequent short-term outcome, however, with respect to long-term treatment a longer time period might be necessary. Therefore, treatment adaptations already within the early weeks of antipsychotic treatment seem to be critical given that response in some FES patients seem to be lagged and might result in false and unnecessary changes of treatment. Future studies are warranted to finally answer this clinically highly relevant question.

\section{CORRELATES AND PREDICTORS OF TREATMENT RESPONSE IN FIRST-EPISODE PATIENTS}

\section{Biological Variables}

Today, advances in genetic research as well as imaging techniques have considerably contributed to a better understanding of the pathophysiological underpinnings of response in FES patients with the latest findings summed up in this paragraph. Especially studies on never-treated first-episode patients are important in this context for antipsychotic treatment has been found to change, e.g., receptor physiology ${ }^{27)}$ or brain morphology. ${ }^{28)}$ Amongst others, polymorphisms in the serotonin $2 \mathrm{~A}$ receptor or the serotonin transporter promoter gene have been associated with the clinical effect of the applied antipsychotic drugs. ${ }^{29,30)}$ In a pharmacogenetic study evaluating 30 variants of dopamine and serotonin candidate genes in 120 FES neuroleptic-naïve patients receiving risperidone monotherapy for 8 weeks, two SNPs in the dopamine D2 receptor and AKT1 were significant predictors of treatment response to risperidone (response defined as PANSS improvement). ${ }^{31)}$ Also, when examining polymorphisms in the $\mathrm{D} 2$ receptor gene in $61 \mathrm{FES}$ patients and a 16-weeks treatment with either risperidone or olanzapine Lencz et $a l{ }^{32)}$ found a significant association between the polymorphisms and response (defined as the absence of delusions, hallucinations or substantial thought disorder). However, there are also negative studies in FES and genetics such as the one by Pelayo-Teran on the catechyl-Omethyltransferase (COMT) Val158Met polymorphism. This study did not find a significant association between the polymorphism and response ( $40 \%$ improvement in the Scale for the Assessment of Negative [SANS] and Positive Symptoms [SAPS]) in 161 FES patients assigned to either haloperidol, olanzapine or risperidone over 6 weeks of treatment. ${ }^{33)}$

Imaging studies using different tools were able to identify variables significantly associated with response in FES patients. Kapur et al., ${ }^{34)}$ for example, using positron emission tomography, found a significant relationship between dopamine D2 occupancy and clinical response in 22 FES patients randomly assigned to 1.0 or $2.5 \mathrm{mg}$ haloperidol with significantly increased response when the D2 occupancy exceeded $65 \%, 72 \%$, and $78 \%$. In a magnetic resonance imaging study by Szeszko et $\mathrm{al}^{35)} 39 \mathrm{FES}$ patients were examined and randomly assigned to risperidone or olanzapine within a 16-week double-blind study defining response via psychosis and disorganization items of the Schedule for Affective Disorders and Schizophrenia Change Version and the improvement item of CGI. Statistical mapping results indicated that responders $(25$ patients) had greater cortical thickness in occipital regions and greater frontal cortical asymmetry compared to non-responders and that among the responders greater 
thickness in temporal regions was furthermore associated with less time to respond. $^{35)}$

In FES patients, Garner et al. ${ }^{36)}$ were furthermore able to show that larger volumes of the pituitary were significantly associated with less improvement in overall psychotic and positive symptoms measured using the Brief Psychotic Rating Scale in a sample of 42 drug-naïve patients treated with quetiapine over 12 weeks. In line with this result are studies postulating a significant influence of the hypothalamic-pituitary-adrenal axis and the immune system in the occurrence of psychosis, presence of clinical symptoms and response in FES patients. ${ }^{37,38)}$ The fact that differences in the response pattern are probably derived by the individual brain physiology are also underlined by differences in the electroencephalography (EEG) profiles comparing FES patients with an early and late response to antipsychotic treatment. ${ }^{39)}$ Altogether, today there are several biological markers known to be associated with the patent's individual response pattern. Some of these variables, such as genetic polymorphisms or morphological brain abnormalities might serve as predictors of response in clinical routine one day allowing an individualized approach of treatment. Until then more research is needed in order to confirm present data concurrently developing strategies to implement such research results into clinical practice.

\section{Clinical and IIIness Associated Variables}

Helping clinicians to identify patients in risk of non-response is believed to be a major step towards optimising therapeutic efforts, therefore in the following the factors most often discussed in the literature will be summarized. One of the variables associated with a greater likelihood of non-response to treatment is the duration of untreated psychosis (DUP). Studies provide estimates of time between the onset of symptoms of schizophrenia and the beginning of treatment varying between 22 weeks to over 150 weeks. $^{40,41)}$ A longer DUP has been linked to a longer time to treatment response in first-episode patients and generally to an unfavourable course of the illness. ${ }^{42,43)}$ In one of the few long-term follow-up studies Bottlender et al. ${ }^{44)}$ were able to show that a longer DUP was associated with more pronounced negative, positive and general psychopathological symptoms as well as a lower global functioning 15 years after the first psychiatric admission, even after effects of other factors, possibly related to the longterm outcome, were controlled for. Such findings underline the importance of establishing health service programs for early detection and treatment of FES patients with the aim to shorten the DUP consequently improving the course and outcome of schizophrenia.

The patient's DUP has been found to be associated with the level of premorbid adjustment, a result that has led to the debate on whether or not DUP is simply an epiphenomenon of premorbid adjustment. ${ }^{45)}$ Poor premorbid adjustment in turn is linked with poor response to antipsychotic treatment $^{46)}$ and it has been hypothesized that the poor premorbid adjustment might result in a reduced chance of detecting psychosis thus, resulting in a prolonged DUP. ${ }^{47)}$ However, when analysing predictors of response in FES patients and the independent evaluation contribution of DUP and premorbid adjustment as well as age at onset, Perkins et al. ${ }^{48)}$ were able to show that a shorter DUP and good premorbid function are independently associated with better response to antipsychotic treatment. Interestingly, both DUP and premorbid adjustment are again linked with the level of negative symptoms, ${ }^{48)}$ but also positive symptoms ${ }^{49)}$ with better premorbid adjustment and a shorter DUP linked to less negative and also positive symptoms. Generally, first-episode patients feature lower levels of negative symptoms compared to multiple episode patients which has been associated to a more favourable response pattern. ${ }^{8)}$ However, there are also conflicting reports from authors finding higher levels of psychopathology, including negative symptoms, to be associated with response in FES patients. ${ }^{50)}$ In terms of positive symptoms there are several authors finding a higher level of positive symptoms associated with better response. ${ }^{10,46)}$ From a clinical point of view this result is not very surprising given that patients with acute psychotic symptoms are known to respond very well to antipsychotic treatment, whereas other dimensions of schizophrenia psychopathology seem to be less responsive. ${ }^{51)}$ In our own working group we analysed predictors of response in a randomized and double-blind trial comparing the efficacy of risperidone and haloperidol and also found that a higher degree of positive baseline symptoms significantly predicted achieving response ( $\geq 50 \%$ PANSS total score improvement from baseline to endpoint). ${ }^{52)}$

We also found that insight into illness was a significant predictor of response namely in that sense that patients with better insight into their illness were the ones achieving response more likely compared to patients with less insight. ${ }^{52)}$ Comparative studies are limited, however, this link between insight and response is somewhat underlined by studies in FES patients reporting that impairments in insight are a strong predictor of relapse and re-admission. ${ }^{53)}$ In terms of treatment tolerability several authors identified 
that the development of neurologic soft signs during antipsychotic treatment was significantly associated with less likelihood of response. ${ }^{10)}$ And in a 1-year follow-up study Prikryl et al. ${ }^{54)}$ examined 92 FES patients evaluating neurological soft signs using the Neurological Evaluation Scale confirming the previous research that neurological soft signs are associated with treatment response and outcome. ${ }^{54)}$ The authors discuss that this association might characterize a subgroup of FES patients with a poor course of illness and outcome.

\section{THERAPEUTIC INTERVENTIONS AND TREATMENT RESPONSE IN FIRST-EPISODE PATIENTS}

\section{Antipsychotics Treatment}

As initially mentioned, FES patients differ from multiple episode patients in so far as a higher proportion of patients show a satisfying response to treatment and outcome. ${ }^{10)}$ Usually the antipsychotic dose required achieving response and remission is lower in FES patients ${ }^{55)}$ with more susceptibility to extrapyramidal side effects in this patient subgroup. ${ }^{18)}$ Since the publication of the pioneering study on the efficacy of antipsychotics in FES patients in the 1970s, response rates to antipsychotic treatment have been found to be high ranging from 46 to $96 \%{ }^{56)}$ With the introduction of the second generation antipsychotics, there has been an ongoing debate about a potential benefit of these compounds in the treatment of FES patients. Some evidence suggested that atypical antipsychotics affect a broader range of schizophrenia's psychopathological symptoms concurrently being better tolerated. ${ }^{57)}$ Especially in terms of negative symptoms, atypical antipsychotics were reported to show superior efficacy in many of the comparator studies with typical compounds. ${ }^{58,59)}$

Lieberman et al. ${ }^{60)}$ compared the efficacy of olanzapine versus haloperidol within a randomized, double-blind trial on 263 first-episode psychosis patients finding no significant difference in terms of the baseline-to-endpoint reductions in symptom severity in the last-observation-carried-forward analyses with a follow-up of 104 weeks. However, when performing mixed-model analysis olanzapine-treated patients had significantly greater decreases in the severity of symptoms measured via the negative and general PANSS subscores and the Montgomery-AsbergDepression Rating Scale. ${ }^{60)}$ Schooler and colleagues examined 555 first-episode patients participating in a double-blind, randomized, controlled flexible-dose trial com- paring risperidone and haloperidol with a median length of treatment of 206 days. ${ }^{61)}$ Authors found a significant improvement in the PANSS and CGI ratings relative to baseline with no significant differences between groups. However, they identified less relapses in the patients with clinical improvement and risperidone treatment compared to those with clinical improvement receiving haloperidol treatment. ${ }^{61)}$ Similarly to their results, Möller $e t$ al. ${ }^{62)}$ in a double-blind randomized controlled trial were not able to observe a significant difference in the psychopathological improvements when comparing 143 FES patients receiving risperidone and 146 patients with haloperidol. Defining response based on the definition proposed by Lieberman et al., ${ }^{60)} 1$ ) a rating of $\leq 3$ in PANSS items $1-3,5,6,2)$ a $\geq 30 \%$ reduction from baseline in PANSS total score and 3) a CGI severity score $\leq 4$, Möller et al. ${ }^{62)}$ again did not find significantly differing response rates comparing risperidone (49.3\%) and haloperidol (49.6\%). However, significantly fewer drop-outs and a lower prevalence of extrapyramidal symptoms were reported in the risperidone group. ${ }^{62)}$ Within the EUFEST study Kahn et $a l{ }^{63)}$ stated that symptom reduction (decrease of the PANSS total score) was virtually the same when comparing the efficacy of haloperidol, amisulpride, olanzapine, quetiapine and ziprasidone in a follow-up duration of 1 year. Again, in agreement with the previously discussed studies, Kahn et al ${ }^{63)}$ also found a higher risk for treatment discontinuation in the haloperidol group. Interestingly, when performing specific response and remission analyses within the EUFEST data, Boter et $a l .{ }^{64)}$ reported a significant difference in the response rates of the patients after one year when defining response as a $\geq 50 \%$ PANSS total score improvement, with patients on a low dose of haloperidol achieving response less likely within the 12 months of treatment compared to amisulpride, olanzapine, or ziprasidone (response rates: $37 \%$ for haloperidol, $67 \%$ for amisulpride, $67 \%$ for olanzapine, $46 \%$ for quetiapine, and $56 \%$ for ziprasidone). The authors explain their differing results (no significant difference in the PANSS total score decrease but in the dichotomised response criterion) by different statistical methods applied when calculating the data. ${ }^{64)}$ In a recently published review on 15 randomized controlled trials with a total of 2,522 patients no significant differences between atypical and typical drugs could be observed for the effect on symptoms or discontinuation rates, ${ }^{65)}$ but atypical compounds were associated with more weight gain whereas typical compounds led to more extrapyramidal side effects so that the authors concluded that the choice of antipsychotic drug in FES 
treatment is probably more influenced by the drug's side effect profile than its efficacy. ${ }^{65)}$ A Cochrane review found current research basis on atypical antipsychotics for FES patients inconclusive, questioning whether the use of atypical antipsychotics would really make the treatment less off-putting and would enhance long-term compliance. ${ }^{66)}$ Some results deriving from imaging studies suggest a biophysiological difference between treatment with atypical and typical antipsychotics in FES patients. Here for example Lieberman et al. $^{67)}$ found significant between-treatment differences in volume changes of magnetic resonance imaging when examining 263 FES patients treated with haloperidol or olanzapine over 104 weeks. The authors reported that haloperidol was associated with significant reductions in gray matter volume whereas olanzapine was not, questioning whether these effects could be due to haloperidol-toxicity or greater therapeutic effects of olanzapine. ${ }^{67)}$ Crespo-Facorro et al. ${ }^{68)}$ found that haloperidol, risperidone and olanzapine had equal effects in the gray matter cortical structure after 1 year of treatment in 38 drug-naïve FES patients. Besides, they reported that atypical antipsychotics had differential effects on lateral ventricle and caudate nucleus volumes. However, due to the very small sample size their results should be discussed with caution.

Taken together, a final recommendation on which antipsychotic class should be administered in order to ensure sufficient and adequate response cannot be made today. Due to the fact that on the one hand a significant benefit of treatment with atypical antipsychotics in terms of response and efficacy has not yet been proven and, on the other hand higher costs are accompanied with the treatment of atypical compounds compared to typical compounds, treatment guidelines are beginning to move away from previous recommendation of atypical antipsychotics as the first-line treatment in patients suffering from their first illness episode as performed within an update by the National Institute for Health and Clinical Excellence (NICE) ${ }^{69)}$ Given that at least some of the current inconsistencies in this field might go back to methodological differences of the trials as well as to differing outcome criteria, future studies are being warranted using standardized outcome criteria in order to provide a valid knowledge basis for treatment recommendations in this patient cohort.

Despite a robust response to antipsychotic treatment in FES patients, a subgroup of patients remains with significant persisting psychotic symptoms not responding well to the first-line antipsychotic treatment applied. ${ }^{70)}$ In their review on the management of incomplete remission and treatment resistance in first-episode psychosis, Lambert et $a{ }{ }^{7)}$ provide detailed recommendations in FES patients in case of non-response conducting the pharmacological management into four stages. The authors emphasize that clinicians should carefully evaluate whether the patient has had received adequate treatment since insufficient pharmacological treatment is one of the most important confounding factors in treatment resistant assessment. ${ }^{7)}$ After combining and augmenting antipsychotic compounds (stage I and II) treatment with clozapine is recommended as stage III and augmentation of clozapine as stage IV. ${ }^{7)}$ Some authors have examined clozapine not as last treatment choice, but as first-line treatment not finding clozapine to be superior compared to comparator drugs. ${ }^{71,72)}$ Agid et al. ${ }^{73)}$ explicitly examined how many FES patients would respond to a second antipsychotic in case of an inadequate response to the first compound and how many patients would respond to clozapine after all. The authors were able to show that in the first run $74.5 \%$ of 244 FES patients responded to antipsychotic treatment (risperidone/olanzapine) with significantly higher rates for the olanzapine-treated patients. In the second trial treatment was switched from olanzapine to risperidone or vice versa and performed in the non-responders of the first run. The response rate dropped dramatically to $16.6 \%$, but was again significantly higher for olanzapine. The response rate climbed up to above $70 \%$ again in those patients with non-response that agreed to clozapine. ${ }^{73)}$ Based on their results it is concluded that individuals should be treated with clozapine in a timely and systematic fashion in case of non-response, possibly useful already as a second-line treatment. ${ }^{74)}$

\section{Non-pharmacological Treatment Approaches}

Especially in patients with insufficient response to antipsychotic treatment, non-pharmacological treatment strategies have been applied most often in order to enhance the antipsychotics' efficacy. Very recently, a case-control study on the effect of electroconvulsive therapy (ECT) in first-episode patients has been published comparing additional ECT-treatment in 74 FES patients to an allocated control group (38 patients) while they had antipsychotic treatment with survival analysis revealing that patients with additional ECT had a significantly higher cumulative response rate than controls. ${ }^{75)}$ And within a naturalistic study in 7 FES patients Suzuki et al. ${ }^{76)}$ reported of a significant improvement of the total score of the Brief Psychiatric Rating Scale (BPRS) one week after the final 
session compared to the total pre-ECT BPRS score. Both studies found ECT well tolerated in FES patients and a valuable treatment option. Studies on the efficacy of other non-pharmacological strategies, e.g,. transcranial magnetic stimulation in patients featuring the first episode of psychosis are still standing out.

\section{Psychotherapeutic Approaches}

Even though FES patients are generally the most responsive to antipsychotic treatment, they have been found to have difficulties accepting their diagnosis, hindering them to engage with their therapy and thus leading to treatment delay or even discontinuation of therapy. ${ }^{77)}$ Early intervention programs incorporating assertive, effective and psychosocial therapy were found to enhance the therapeutic alliance, acceptance of treatment and with it the outcome of the illness. Effects on the acute response to treatment have not been in the focus of research which is why only a short summary covers this topic. Multi-element programs offer a comprehensive array of specialized in- and outpatient services supporting FES patients in problems such as engaging with the health systems or in case of substance abuse. ${ }^{78)}$ Single-element interventions, mainly incorporating cognitive-behavioural therapy (CBT) as well as family interventions have evaluated the effectiveness of specific psychosocial interventions. ${ }^{78)}$ Generally, only few studies evaluating CBT in FES patients are available with a reliable design and mainly only examining psychotic symptom reduction or early recovery. CBT was found to help speeding the recovery process even though no significant gains remained compared to treatment as usual at follow-up. ${ }^{79)}$ Besides CBT, family interventions have aimed at reducing the adverse family atmosphere and preventing relapse or hospital admission. Such therapeutic approaches were found to vary widely with conflicting evidence in terms of the effect on symptoms, burden, social outcome or service satisfaction. ${ }^{80)}$ As Crespo-Facorro et al. ${ }^{79)}$ conclude in their update on pharmacological and psychosocial interventions, there is a great need for well-designed studies to further examine the effectiveness of CBT and family interventions in patients with a first-episode of schizophrenia, especially in terms of the acute response to treatment. Currently, optimal treatment in FES patients incorporates both psychopharmacological as well as psychosocial treatment approaches.

\section{CONCLUSION}

Response to treatment in FES patients has been found to be robust resulting in favourable response rates ranging up to $80 \%$, yet the time course of response varies considerably. In FES patients response within the first treatment weeks was found to reliably predict subsequent response in the short-term but not in the long-term treatment. Therefore, switching strategies in case of early non-response should be carefully re-evaluated and critically discussed. Several significant predictors of response such as genetic polymorphisms and brain morphologic changes have been identified. A shorter DUP and good premorbid adjustment were among the most reliable clinical predictors of response to treatment. In terms of the most effective antipsychotic treatment strategy current study results do not give clear guidance yet. However, there are promising results of clozapine and additional electroconvulsive therapy in patients with primary non-response. Besides, early intervention strategies using psychosocial approaches such as cognitive behavioural therapy or family interventions were found to enhance the therapeutic alliance, acceptance of treatment and with it the outcome of the illness. Future research is needed in order to further examine the effects of single antipsychotic compounds. Apart from that, more research on pharmacogenetics is mandatory in order to be able to achieve personalized treatment in the future, preventing patients from ineffective compounds, reducing side effects and with this enhancing adherence to treatment and improving the outcome of schizophrenia.

\section{REFERENCES}

1. Frangou S, Byrne P. How to manage the first episode of schizophrenia. BMJ 2000;321:522-523.

2. Redmond C, Larkin M, Harrop C. The personal meaning of romantic relationships for young people with psychosis. Clin Child Psychol Psychiatry 2010;15:151-170.

3. Schnabel R, Friedel H, Erfurth A, Angermayer M, Clouth J, Eichmann F. Predisposing factors for early retirement in patients with schizophrenia in Germany. Eur J Health Econ 2008;9:265-274.

4. Harrison G, Hopper K, Craig T, Laska E, Siegel C, Wanderling J, et al. Recovery from psychotic illness: a 15and 25-year international follow-up study. Br J Psychiatry 2001;178:506-517.

5. Loebel AD, Lieberman JA, Alvir JM, Mayerhoff DI, Geisler SH, Szymanski SR. Duration of psychosis and outcome in first-episode schizophrenia. Am J Psychiatry 1992;149:11831188.

6. International Early Psychosis Association Writing Group. International clinical practice guidelines for early psychosis. Br J Psychiatry Suppl 2005;48:s120-s124.

7. Lambert M, Naber D, Huber CG. Management of incomplete 
remission and treatment resistance in first-episode psychosis. Expert Opin Pharmacother 2008;9:2039-2051.

8. Jäger M, Riedel M, Messer T, Laux G, Pfeiffer H, Naber $\mathrm{D}$, et al. Psychopathological characteristics and treatment response of first episode compared with multiple episode schizophrenic disorders. Eur Arch Psychiatry Clin Neurosci 2007;257:47-53.

9. Falkai P, Wobrock T, Lieberman J, Glenthoj B, Gattaz WF, Möller HJ; WFSBP Task Force on Treatment Guidelines for Schizophrenia. World Federation of Societies of Biological Psychiatry (WFSBP) guidelines for biological treatment of schizophrenia, Part 1: acute treatment of schizophrenia. World J Biol Psychiatry 2005;6:132-191.

10. Robinson DG, Woerner MG, Alvir JM, Geisler S, Koreen A, Sheitman B, et al. Predictors of treatment response from a first episode of schizophrenia or schizoaffective disorder. Am J Psychiatry 1999;156:544-549.

11. Emsley R, Rabinowitz J, Medori R. Time course for antipsychotic treatment response in first-episode schizophrenia. Am J Psychiatry 2006;163:743-745.

12. Birchwood M, Todd P, Jackson C. Early intervention in psychosis. The critical period hypothesis. Br J Psychiatry Suppl 1998;172:53-59.

13. McGlashan TH. A selective review of recent North American long-term followup studies of schizophrenia. Schizophr Bull 1988; 14:515-542.

14. Leucht S, Kane JM. Measurement-based psychiatry: definitions of response, remission, stability, and relapse in schizophrenia. J Clin Psychiatry 2006;67:1813-1814.

15. Leucht S, Davis JM, Engel RR, Kane JM, Wagenpfeil S. Defining 'response' in antipsychotic drug trials: recommendations for the use of scale-derived cutoffs. Neuropsychopharmacology 2007;32:1903-1910.

16. Lieberman J, Jody D, Geisler S, Alvir J, Loebel A, Szymanski S, et al. Time course and biologic correlates of treatment response in first-episode schizophrenia. Arch Gen Psychiatry 1993;50:369-376.

17. Emsley RA. Risperidone in the treatment of first-episode psychotic patients: a double-blind multicenter study. Risperidone Working Group. Schizophr Bull 1999;25:721-729.

18. Sanger TM, Lieberman JA, Tohen M, Grundy S, Beasley C $\mathrm{Jr}$, Tollefson GD. Olanzapine versus haloperidol treatment in first-episode psychosis. Am J Psychiatry 1999;156:79-87.

19. Agid O, Kapur S, Arenovich T, Zipursky RB. Delayed-onset hypothesis of antipsychotic action: a hypothesis tested and rejected. Arch Gen Psychiatry 2003;60:1228-1235.

20. Leucht S, Busch R, Hamann J, Kissling W, Kane JM. Early-onset hypothesis of antipsychotic drug action: a hypothesis tested, confirmed and extended. Biol Psychiatry 2005; 57:1543-1549.

21. Kinon BJ, Chen L, Ascher-Svanum H, Stauffer VL, KollackWalker S, Sniadecki JL, et al. Predicting response to atypical antipsychotics based on early response in the treatment of schizophrenia. Schizophr Res 2008;102:230-240.

22. Kinon BJ, Chen L, Ascher-Svanum H, Stauffer VL, KollackWalker S, Zhou W, et al. Early response to antipsychotic drug therapy as a clinical marker of subsequent response in the treatment of schizophrenia. Neuropsychopharmacology 2010;35:581-590.

23. Derks EM, Fleischhacker WW, Boter H, Peuskens J, Kahn RS; EUFEST Study Group. Antipsychotic drug treatment in first-episode psychosis: should patients be switched to a different antipsychotic drug after 2, 4, or 6 weeks of nonresponse? J Clin Psychopharmacol 2010;30:176-180.

24. Gallego JA, Robinson DG, Sevy SM, Napolitano B,
McCormack J, Lesser ML, et al. Time to treatment response in first-episode schizophrenia: should acute treatment trials last several months? J Clin Psychiatry 2011;72:1691-1696.

25. Schennach-Wolff R, Seemüller FH, Mayr A, Maier W, Klingberg S, Heuser I, et al. An early improvement threshold to predict response and remission in first-episode schizophrenia. Br J Psychiatry 2010;196:460-466.

26. Schennach R, Riesbeck, M, Mayr A, Seemüller F, Maier W, Klingberg S, et al. Should early improvement be re-defined to better predict the maintenance of response in FES patients? Acta Psychiatrica Scandinavic 2012 [In press].

27. Silvestri S, Seeman MV, Negrete JC, Houle S, Shammi CM, Remington GJ, et al. Increased dopamine D2 receptor binding after long-term treatment with antipsychotics in humans: a clinical PET study. Psychopharmacology (Berl) 2000;152:174-180.

28. Deng MY, McAlonan GM, Cheung C, Chiu CP, Law CW, Cheung $\mathrm{V}$, et al. A naturalistic study of grey matter volume increase after early treatment in anti-psychotic naïve, newly diagnosed schizophrenia. Psychopharmacology (Berl) 2009; 206:437-446.

29. Dolzan V, Serretti A, Mandelli L, Koprivsek J, Kastelic M, Plesnicar BK. Acute antipyschotic efficacy and side effects in schizophrenia: association with serotonin transporter promoter genotypes. Prog Neuropsychopharmacol Biol Psychiatry 2008;32:1562-1566.

30. Rasmussen H, Ebdrup BH, Erritzoe D, Aggernaes B, Oranje $\mathrm{B}$, Kalbitzer J, et al. Serotonin $2 A$ receptor blockade and clinical effect in first-episode schizophrenia patients treated with quetiapine. Psychopharmacology (Berl) 2011;213:583592.

31. Ikeda M, Yamanouchi Y, Kinoshita Y, Kitajima T, Yoshimura R, Hashimoto S, et al. Variants of dopamine and serotonin candidate genes as predictors of response to risperidone treatment in first-episode schizophrenia. Pharmacogenomics 2008;9:1437-1443.

32. Lencz T, Robinson DG, Xu K, Ekholm J, Sevy S, GunduzBruce $\mathrm{H}$, et al. DRD2 promoter region variation as a predictor of sustained response to antipsychotic medication in first-episode schizophrenia patients. Am J Psychiatry 2006;163:529-531.

33. Pelayo-Terán JM, Pérez-Iglesias R, Vázquez-Bourgon J, Mata I, Carrasco-Marín E, Vázquez-Barquero JL, et al. Catechol-O-methyltransferase Val158Met polymorphism and negative symptoms after acute antipsychotic treatment in first-episode non-affective psychosis. Psychiatry Res 2011; 185:286-289.

34. Kapur S, Zipursky R, Jones C, Remington G, Houle S. Relationship between dopamine $D(2)$ occupancy, clinical response, and side effects: a double-blind PET study of first-episode schizophrenia. Am J Psychiatry 2000;157:514520.

35. Szeszko PR, Narr KL, Phillips OR, McCormack J, Sevy S, Gunduz-Bruce $\mathrm{H}$, et al. Magnetic resonance imaging predictors of treatment response in first-episode schizophrenia. Schizophr Bull 2012;38:569-578.

36. Garner B, Berger GE, Nicolo JP, Mackinnon A, Wood SJ, Pariante $\mathrm{CM}$, et al. Pituitary volume and early treatment response in drug-naïve first-episode psychosis patients. Schizophr Res 2009;113:65-71.

37. Belvederi Murri M, Pariante CM, Dazzan P, Hepgul N, Papadopoulos AS, Zunszain P, et al. Hypothalamic-pituitaryadrenal axis and clinical symptoms in first-episode psychosis. Psychoneuroendocrinology 2012;37:629-644.

38. van Venrooij JA, Fluitman SB, Lijmer JG, Kavelaars A, 
Heijnen CJ, Westenberg HG, et al. Impaired neuroendocrine and immune response to acute stress in medication-naive patients with a first episode of psychosis. Schizophr Bull 2012;38:272-279.

39. Merlo MC, Kleinlogel H, Koukkou M. Differences in the EEG profiles of early and late responders to antipsychotic treatment in first-episode, drug-naive psychotic patients. Schizophr Res 1998;30:221-228.

40. McGlashan TH. Duration of untreated psychosis in firstepisode schizophrenia: marker or determinant of course? Biol Psychiatry 1999;46:899-907.

41. Norman RM, Malla AK. Duration of untreated psychosis: a critical examination of the concept and its importance. Psychol Med 2001;31:381-400.

42. Addington J, Van Mastrigt S, Addington D. Duration of untreated psychosis: impact on 2-year outcome. Psychol Med 2004;34:277-284.

43. de Haan L, Linszen DH, Lenior ME, de Win ED, Gorsira R. Duration of untreated psychosis and outcome of schizophrenia: delay in intensive psychosocial treatment versus delay in treatment with antipsychotic medication. Schizophr Bull 2003;29:341-348.

44. Bottlender R, Sato T, Jäger M, Wegener U, Wittmann J, Strauss A, et al. The impact of the duration of untreated psychosis prior to first psychiatric admission on the 15-year outcome in schizophrenia. Schizophr Res 2003;62:37-44.

45. Larsen TK, Moe LC, Vibe-Hansen L, Johannessen JO. Premorbid functioning versus duration of untreated psychosis in 1 year outcome in first-episode psychosis. Schizophr Res 2000;45:1-9.

46. Crespo-Facorro B, Pelayo-Terán JM, Pérez-Iglesias R, Ramírez-Bonilla M, Martínez-García O, Pardo-García G, et al. Predictors of acute treatment response in patients with a first episode of non-affective psychosis: sociodemographics, premorbid and clinical variables. $J$ Psychiatr Res 2007;41:659-666.

47. Verdoux H, Liraud F, Bergey C, Assens F, Abalan F, van Os J. Is the association between duration of untreated psychosis and outcome confounded? A two year follow-up study of first-admitted patients. Schizophr Res 2001;49:231241.

48. Perkins D, Lieberman J, Gu H, Tohen M, McEvoy J, Green A, et al; HGDH Research Group. Predictors of antipsychotic treatment response in patients with first-episode schizophrenia, schizoaffective and schizophreniform disorders. Br J Psychiatry 2004;185:18-24.

49. Schimmelmann BG, Huber CG, Lambert M, Cotton S, McGorry PD, Conus P. Impact of duration of untreated psychosis on pre-treatment, baseline, and outcome characteristics in an epidemiological first-episode psychosis cohort. J Psychiatr Res 2008;42:982-990.

50. Cesková E, Prikryl R, Kaspárek T, Ondrusová M. Psychopathology and treatment responsiveness of patients with first-episode schizophrenia. Neuropsychiatr Dis Treat 2005; 1:179-185.

51. Addington J, Leriger E, Addington D. Symptom outcome 1 year after admission to an early psychosis program. Can J Psychiatry 2003;48:204-207.

52. Schennach-Wolff R, Jäger M, Mayr A, Meyer S, Kühn KU, Klingberg S, et al. Predictors of response and remission in the acute treatment of first-episode schizophrenia patients--is it all about early response? Eur Neuropsychopharmacol 2011;21:370-378.

53. Drake RJ, Dunn G, Tarrier N, Bentall RP, Haddock G, Lewis SW. Insight as a predictor of the outcome of first- episode nonaffective psychosis in a prospective cohort study in England. J Clin Psychiatry 2007;68:81-86.

54. Prikryl R, Ceskova E, Kasparek T, Kucerova H. Neurological soft signs and their relationship to 1-year outcome in first-episode schizophrenia. Eur Psychiatry 2007;22:499504.

55. Oosthuizen P, Emsley R, Jadri Turner H, Keyter N. A randomized, controlled comparison of the efficacy and tolerability of low and high doses of haloperidol in the treatment of first-episode psychosis. Int $J$ Neuropsychopharmacol 2004; 7:125-131.

56. Robinson DG, Woerner MG, Delman HM, Kane JM. Pharmacological treatments for first-episode schizophrenia. Schizophr Bull 2005;31:705-722.

57. Kinon BJ, Lieberman JA. Mechanisms of action of atypical antipsychotic drugs: a critical analysis. Psychopharmacology (Berl) 1996;124:2-34.

58. Möller HJ. Management of the negative symptoms of schizophrenia: new treatment options. CNS Drugs 2003;17:793823.

59. Möller HJ. State of the art of drug treatment of schizophrenia and the future position of the novel/atypical antipsychotics. World J Biol Psychiatry 2000;1:204-214.

60. Lieberman JA, Tollefson G, Tohen M, Green AI, Gur RE, Kahn R, et al; HGDH Study Group. Comparative efficacy and safety of atypical and conventional antipsychotic drugs in first-episode psychosis: a randomized, double-blind trial of olanzapine versus haloperidol. Am J Psychiatry 2003; 160:1396-1404.

61. Schooler N, Rabinowitz J, Davidson M, Emsley R, Harvey $\mathrm{PD}$, Kopala L, et al; Early Psychosis Global Working Group. Risperidone and haloperidol in first-episode psychosis: a long-term randomized trial. Am J Psychiatry 2005;162:947953.

62. Möller HJ, Riedel M, Jäger M, Wickelmaier F, Maier W, $\mathrm{Kühn} \mathrm{KU}$, et al. Short-term treatment with risperidone or haloperidol in first-episode schizophrenia: 8-week results of a randomized controlled trial within the German Research Network on Schizophrenia. Int J Neuropsychopharmacol 2008;11:985-997.

63. Kahn RS, Fleischhacker WW, Boter H, Davidson M, Vergouwe Y, Keet IP, et al; EUFEST study group. Effectiveness of antipsychotic drugs in first-episode schizophrenia and schizophreniform disorder: an open randomised clinical trial. Lancet 2008;371:1085-1097.

64. Boter H, Peuskens J, Libiger J, Fleischhacker WW, Davidson M, Galderisi S, et al; EUFEST study group. Effectiveness of antipsychotics in first-episode schizophrenia and schizophreniform disorder on response and remission: an open randomized clinical trial (EUFEST). Schizophr Res 2009;115:97-103.

65. Crossley NA, Constante M, McGuire P, Power P. Efficacy of atypical $v$. typical antipsychotics in the treatment of early psychosis: meta-analysis. Br J Psychiatry 2010;196:434-439.

66. Rummel C, Hamann J, Kissling W, Leucht S. New generation antipsychotics for first episode schizophrenia. Cochrane Database Syst Rev 2003;(4):CD004410.

67. Lieberman JA, Tollefson GD, Charles C, Zipursky R, Sharma T, Kahn RS, et al; HGDH Study Group. Antipsychotic drug effects on brain morphology in first-episode psychosis. Arch Gen Psychiatry 2005;62:361-370.

68. Crespo-Facorro B, Roiz-Santiáñez R, Pérez-Iglesias R, Pelayo-Terán JM, Rodríguez-Sánchez JM, TordesillasGutiérrez D, et al. Effect of antipsychotic drugs on brain morphometry. A randomized controlled one-year follow-up 
study of haloperidol, risperidone and olanzapine. Prog Neuropsychopharmacol Biol Psychiatry 2008;32:1936-1943.

69. National Institute for Clinical Excellence. Schizophrenia. NICE Clinical Guideline 82. London:NICE;2009.

70. Manchanda R, Norman RM, Malla AK, Harricharan R, Northcott S. Persistent psychoses in first episode patients. Schizophr Res 2005;80:113-116.

71. Lieberman JA, Phillips M, Gu H, Stroup S, Zhang P, Kong $\mathrm{L}$, et al. Atypical and conventional antipsychotic drugs in treatment-naive first-episode schizophrenia: a 52-week randomized trial of clozapine vs chlorpromazine. Neuropsychopharmacology 2003;28:995-1003.

72. Woerner MG, Robinson DG, Alvir JM, Sheitman BB, Lieberman JA, Kane JM. Clozapine as a first treatment for schizophrenia. Am J Psychiatry 2003;160:1514-1516.

73. Agid O, Arenovich T, Sajeev G, Zipursky RB, Kapur S, Foussias G, et al. An algorithm-based approach to firstepisode schizophrenia: response rates over 3 prospective antipsychotic trials with a retrospective data analysis. $J$ Clin Psychiatry 2011;72:1439-1444.

74. Agid O, Remington G, Kapur S, Arenovich T, Zipursky RB. Early use of clozapine for poorly responding first-episode psychosis. J Clin Psychopharmacol 2007;27:369-373.

75. Zhang ZJ, Chen YC, Wang HN, Wang HH, Xue YY, Feng
$\mathrm{SF}$, et al. Electroconvulsive therapy improves antipsychotic and somnographic responses in adolescents with first-episode psychosis - A case-control study. Schizophr Res 2012; 137:97-103.

76. Suzuki K, Awata S, Takano T, Ebina Y, Takamatsu K, Kajiwara $\mathrm{T}$, et al. Improvement of psychiatric symptoms after electroconvulsive therapy in young adults with intractable first-episode schizophrenia and schizophreniform disorder. Tohoku J Exp Med 2006;210:213-220.

77. Ohlsen RI, O'Toole MS, Purvis RG, Walters JT, Taylor TM, Jones HM, et al. Clinical effectiveness in first-episode patients. Eur Neuropsychopharmacol 2004;14(Suppl 4): S445-S451.

78. Penn DL, Waldheter EJ, Perkins DO, Mueser KT, Lieberman JA. Psychosocial treatment for first-episode psychosis: a research update. Am J Psychiatry 2005;162:22202232.

79. Crespo-Facorro B, Pérez-Iglesias R, González-Blanch C, Mata I. Treatment of the first episode of schizophrenia: an update on pharmacologic and psychological interventions. Curr Psychiatry Rep 2008;10:202-209.

80. Askey R, Gamble C, Gray R. Family work in first-onset psychosis: a literature review. J Psychiatr Ment Health Nurs 2007; 14:356-365. 